(c) 2019 Universidad Nacional Autónoma de México, Facultad de Estudios Superiores Zaragoza.

Este es un artículo Open Access bajo la licencia CC BY-NC-ND (http://creativecommons.org/licenses/by-nc-nd/4.0/).

TIP Revista Especializada en Ciencias Químico-Biológicas, 22: 1-16, 2019.

DOI: 10.22201/fesz.23958723e.2019.0.182

\title{
Telas de carbón activado: generalidades y aplicaciones
}

\author{
Yohana Yazmín García-Guel ${ }^{1 \mathrm{a}}$, Elia Martha Múzquiz-Ramos ${ }^{1 \mathrm{~b}}$ \\ y Jorge Carlos Ríos-Hurtado* \\ ${ }^{1}$ Facultad de Ciencias Químicas, Universidad Autónoma de Coahuila, Blvd. Venustiano \\ Carranza y José Cárdenas Valdés, Saltillo 25280, Coahuila, México. ${ }^{2}$ Facultad de \\ Metalurgia, Universidad Autónoma de Coahuila, Monclova 25710, Coahuila, México. \\ E-mail: 1aYohana_0512@hotmail.com, ${ }^{1 b}$ emuzquiz@uadec.edu.mx
}

\begin{abstract}
RESUMEN
Los carbones activados (CA) son de gran interés debido a las excepcionales propiedades físicas y químicas que poseen, estos materiales se presentan en forma de gránulos o polvos, pero recientemente se ha comercializado una nueva forma de CA conocida como Fibra de Carbón Activado (FCA), que se puede fabricar en dos presentaciones, como tela y como fieltro. Las Telas de carbón activado (TCA) son materiales que poseen excelentes propiedades que las hacen superiores en comparación con las formas tradicionales y se producen a partir de precursores, mediante diversos procesos que incluyen activación física o química, entre los agentes impregnantes más utilizados se encuentran el $\mathrm{KOH}, \mathrm{H}_{3} \mathrm{PO}_{4}, \mathrm{ZnCl}_{2}, \mathrm{AlCl}_{3}, \mathrm{NH}_{4} \mathrm{Cl}, \mathrm{Na}_{2} \mathrm{CO}_{3}$ y $\mathrm{K}_{2} \mathrm{CO}_{3}$, cuya función principal es servir como deshidratantes impidiendo al mismo tiempo la producción de alquitranes. Las características y propiedades que adquieren las TCA dependen de la naturaleza del material que se utilizó para producirlas, estas características han sido aprovechadas en una gran cantidad de aplicaciones, como: medicina, sistemas de soporte de catalizadores, en la industria para la adsorción de contaminantes, purificación de aguas y tratamiento de aguas residuales, entre otras. Esta revisión muestra las generalidades y aplicaciones en estudios recientes y resume las aplicaciones de las TCA de las diferentes investigaciones realizadas, así como su proceso de obtención.
\end{abstract}

Palabras Clave: carbones activados, tela de carbón activado, precursores, impregnantes, activación.

\section{Activated carbon cloths: approaches and applications}

\begin{abstract}
Activated carbons (AC) are of special interest due to their exceptional physical and chemical properties, these materials are in the form of granules or powders, but recently a new form of AC has been commercialized which is also known as Activated Carbon Fiber (ACF), and is manufactured in two presentations, cloth and felt. Activated carbon cloths (ACC) are materials that have excellent properties making them superior compared to traditional forms and are produced from precursors, through various processes that include physical and chemical activation, among the most commonly used impregnating agents are $\mathrm{KOH}, \mathrm{H}_{3} \mathrm{PO}_{4}, \mathrm{ZnCl}_{2}, \mathrm{AlCl}_{3}, \mathrm{NH}_{4} \mathrm{Cl}, \mathrm{Na}_{2} \mathrm{CO}_{3}$ and $\mathrm{K}_{2} \mathrm{CO}_{3}$, whose main function is to serve as dehydrators while preventing tars production. The characteristics and properties of the ACC depend on the nature of the material that was used to produce it, these characteristics have been used in a large number of applications, such as medicine, catalyst support systems, in the industry for the absorption of pollutants, water purification and waste water treatment, among others. This review shows the generalities and applications in recent studies and summarizes TCA applications from the different investigations carried out, as well as the process for obtaining them.
\end{abstract}

Key Words: activated carbons, activated carbon cloths, precursors, impregnants, activation.

Nota: Artículo recibido el 15 de octubre del 2018 y aceptado el 24 de junio del 2019. 


\section{INTRODUCCIÓN}

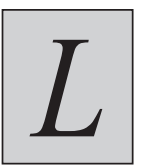

os carbones activados (CA) son de especial interés debido a las excepcionales propiedades físicas y químicas que poseen, como la porosidad, alta área superficial, capacidad de adsorción, estabilidad química, resistencia a la corrosión, resistencia térmica y conductividad eléctrica (Fernández, Bonastre, Molina, del Río \& Cases, 2017). El volumen de los poros en carbones activados es típicamente determinado como mayor que 0.2 $\mathrm{mL} / \mathrm{g}$ y el área superficial interna es, generalmente, entre 400 a $1,500 \mathrm{~m}^{2} / \mathrm{g}$. Esta área es bastante grande si se tiene en cuenta que la superficie específica de una esfera de carbón sin porosidad con diámetro de 0.015 a $0.025 \mathrm{~mm}$ es alrededor de $3.86 \times 10^{-4} \mathrm{~m}^{2} / \mathrm{g}$ (Navarro \& Vargas, 2010; Leyva, Díaz, Guerrero, Mendoza \& Aragón, 2004).

La superficie de los carbones puede encontrarse combinada, en mayor o menor proporción, con otros átomos o grupos de átomos distintos al carbono (heteroátomos), entre los que figuran los grupos carboxílicos, lactonas, fenólicos y carbonilos. Todos los carbones presentan, en principio, un carácter hidrófobo, que puede ser disminuido por la adición de ciertos grupos superficiales, lo que puede conseguirse por oxidación con algún tipo de agente oxidante que crea grupos oxigenados, dando lugar a la adsorción de moléculas de agua, que a su vez adsorberán nuevas moléculas por formación de puentes de hidrógeno; de esta forma se incrementa el carácter hidrófilo, que favorece la adsorción de compuestos inorgánicos en fase acuosa (Hernández-Rodríguez, OteroCalvis, Falcón-Hernández \& Yperman, 2017). Existen algunos materiales de partida para obtener carbones activados, estas materias primas deben tener alto contenido de carbono y bajo contenido de material mineral, además, deben ser de fácil activación, tener un alto rendimiento, tener baja degradación durante su almacenamiento y sobre todo bajo costo. Entre los materiales precursores que se pueden utilizar se encuentran: algas, cáscara de arroz, lignina, aserrín, cáscara de semilla de algodón, lignito, lodos ácidos de petróleo, madera, carbón mineral, huesos de frutas (Luna, González, Gordon \& Martín, 2007), melaza, carbón vegetal, desperdicios de pasta de papel, negro de humo, residuos de carne y sangre, olotes, huesos, desechos de destilería, pescado, cereales, cuesco de palma africana, turba, carbohidratos, coque de petróleo, granos de café, hollín, cáscara de nueces, grafito (Caglayan \& Aksoylu, 2013), cáscara de coco (Song, Liu, Cheng \& Qu, 2010), cáscara de frutas (Tongpoothorn, Sriuttha, Homchan, Chanthai \& Ruangviriyacha, 2011) y residuo de tabaco (Kilic, Apaydin-Varol \& Pütün, 2011).

Recientemente se ha comercializado una nueva forma de carbón activado que se le conoce como Fibra de Carbón Activado (FCA) y se fabrica en dos presentaciones, como tela y como fieltro (Leyva Ramos, Díaz Flores, Guerrero
Coronado, Mendoza Barrón \& Aragón Piña, 2004; Guedidi, Reinert, Soneda, Bellakhal \& Duclaux, 2014). A diferencia del fieltro, la TCA se teje mediante un proceso de hilado. Las telas de carbón activado (TCA) han sido consideradas como un sustrato flexible prometedor debido a su economía, su facilidad de manejo, su gran área superficial, su integridad mecánica y su excelente conductividad (Zhao et al., 2008; Ouyang et al., 2018).

Este artículo muestra una gran variedad de aplicaciones de las TCA, los métodos para su preparación, los diferentes agentes impregnantes que se pueden utilizar para su activación y las ventajas y desventajas de los diferentes tipos de activación. Se revisaron las distintas características y propiedades que pueden adquirir las TCA dependiendo del material polimérico que se utiliza para producirlas $\mathrm{y}$, además, se reportan diferentes estudios realizados por algunos investigadores, que prepararon tela de carbón recubierta con diversos tipos de materiales.

\section{Propiedades de las TCA}

Las Telas de carbón activado (TCA) son materiales que poseen elevadas porosidades (principalmente microporos) (Estévez, Moreno \& Vargas, 2006), gran área superficial (1000 - 2100 $\mathrm{m}^{2} / \mathrm{g}$ ), pequeño diámetro de la fibra, una cinética de adsorción más rápida en comparación con las formas tradicionales de carbón activado, una fácil regeneración, fácil accesibilidad de los poros, distribución de tamaños de poros estrechos, gran capacidad de adsorción para bajas concentraciones de adsorbatos y propiedades específicas de la superficie. $\mathrm{Su}$ módulo de elasticidad puede oscilar entre 230 y $380 \mathrm{GPa}$, resistencia a la tracción entre 1.8 y $2.6 \mathrm{GPa}$ y deformación por falla entre $0.5 \%$ y $1 \%$ (Canal \& Ginebra, 2011). Las características mencionadas hacen que este material sea superior en comparación con el carbón activado granular (CAG) y el carbón activado en polvo (CAP) (Gineys, Benoit, Cohaut, Béguin \& Delpeux-Ouldriane, 2017). En la Figura 1 se muestran los diferentes tipos de carbón adsorbentes; en ella se puede observar el CAP (Figura 1a) y el CAG (Figura 1b), además de las TCA (Figura 1c) (Menéndez-Díaz \& MartínGullon, 2006).

La estructura porosa de las TCA está principalmente constituida por microporos mientras que en las formas tradicionales tienen estructura porosa muy compleja formada por microporos, mesoporos y macroporos. Los diámetros de las fibras de las TCA son (0.006 a $0.017 \mathrm{~mm})$, en promedio 100 veces menores que los diámetros de las partículas de carbón activado en forma granular (1 a $3 \mathrm{~mm}$ ) y ligeramente menores que los diámetros de las partículas de carbón activado en forma de polvo $(0.015$ a $0.025 \mathrm{~mm})$. Por lo tanto, la velocidad de adsorción en las TCA es mucho más rápida que las formas tradicionales del carbón activado (Leyva Ramos, 
Díaz Flores, Guerrero Coronado, Mendoza Barrón, \& Aragón Piña, 2004). Estas razones, sumadas a la fácil manipulación en su aplicación, las han convertido en adsorbentes muy prometedores en la retención de contaminantes, ya que, gracias a su forma fibrosa delgada, se produce una alta cinética de adsorción intraparticular tanto en fase acuosa como gaseosa (Rodríguez, Giraldo \& Moreno, 2007).

\section{Activación de las Telas de Carbón}

Los diferentes pasos para la preparación de TCA a partir de precursores incluyen el hilado, la estabilización $\left(200{ }^{\circ} \mathrm{C}\right.$ - $400{ }^{\circ} \mathrm{C}$ en el aire), carbonización y activación. Primero, las fibras o hilos se pueden tejer en telas, que se pueden agrupar en varios modos básicos de tejido o textil como se observa en la Figura 2; la tela de tejido liso se muestra en la Figura 2a, donde el hilo de relleno se alterna hacia arriba y debajo del hilo de urdimbre sucesivo; la alta densidad de entrelazado de hilos proporciona un máximo de cobertura e impermeabilidad; la Figura $2 \mathrm{~b}$ muestra el tejido de la tela de sarga cruzada, con una línea diagonal afilada, que se produce cuando el hilo de urdimbre se cruza dos o más hilos de relleno; en la Figura 2c se ven las telas satinadas, que se caracterizan por el entrelazado espaciado regularmente a intervalos amplios, produciendo telas permeables con una superficie lisa (Matatov-Meytal \& Sheintuch, 2002). Después de la estabilización, las fibras o los tejidos se someten a un tratamiento térmico (carbonización) a una temperatura de aproximadamente $800{ }^{\circ} \mathrm{C}$ a $1000{ }^{\circ} \mathrm{C}$ en una atmósfera inerte (Tripathi, Singh, Sathe, Thakare \& Singh, 2018). Para la preparación de TCA se utilizan como precursores diversos materiales poliméricos, como nylon, rayón, celulosa, resina fenólica, poliacrilonitrilo (PAN) y brea (Matovic et al., 2016; Babic, Milonjic, Polovina, \& Kaludierovic, 1999).

Para la producción de TCA, se distinguen comúnmente dos métodos de activación: la física y la química (Ospina-Guarín, Buitrago Sierra \& López López, 2014; Peng \& Lin, 2017). En el esquema de la Figura 3 se muestra la comparación entre los dos procedimientos que se utilizan para la activación de las TCA. La gasificación parcial de un carbonizado con gases oxidantes como el $\mathrm{CO}_{2}$ y el vapor de agua constituye la activación física; por lo general se desarrolla en dos etapas, la carbonización del precursor y la gasificación controlada del carbonizado (J. Filippín, S. Luna, T. Pozzi \& D. Pérez, 2017). En la activación química, los materiales de partida

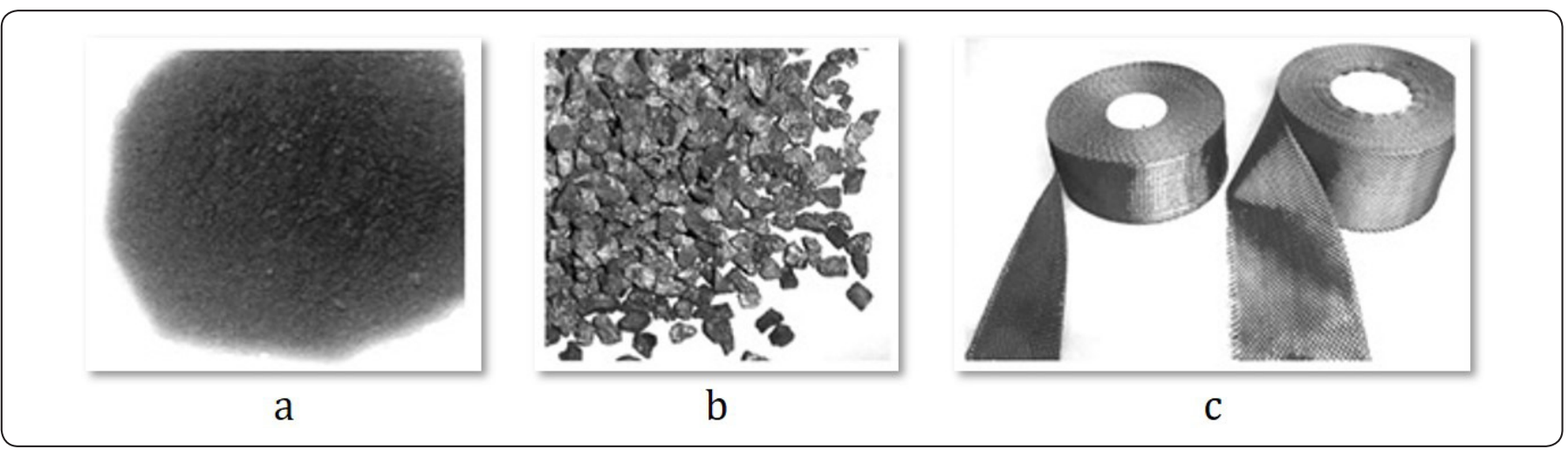

Figura 1. Tipos de carbón activado: (a) CAP; (b) CAG y (c) TCA. Modificada de (Menéndez-Díaz \& Martín-Gullón, 2006).

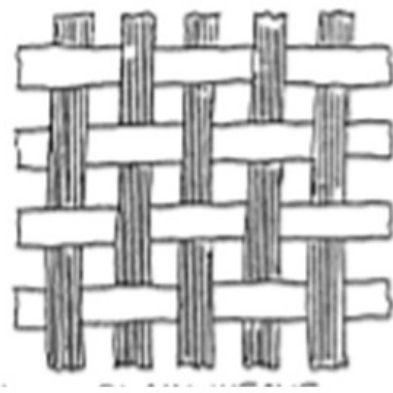

a)

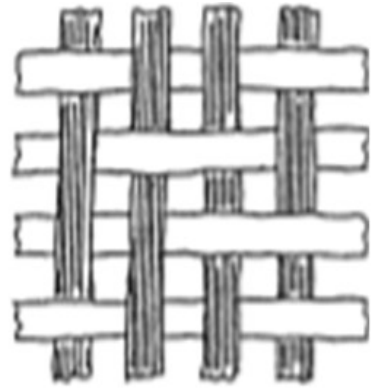

b)

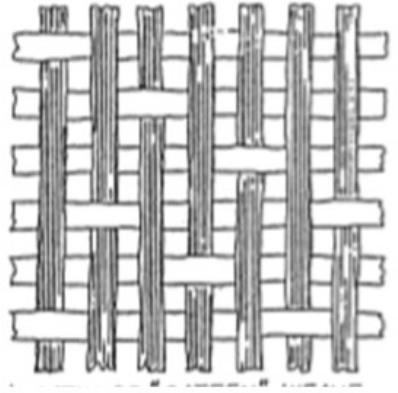

c)

Figura 2. Principales tipos de tejidos textiles de las TCA: (a) tejido liso; (b) tejido de sarga y (c) tejido satinado Modificada de (MatatovMeytal \& Sheintuch, 2002). 


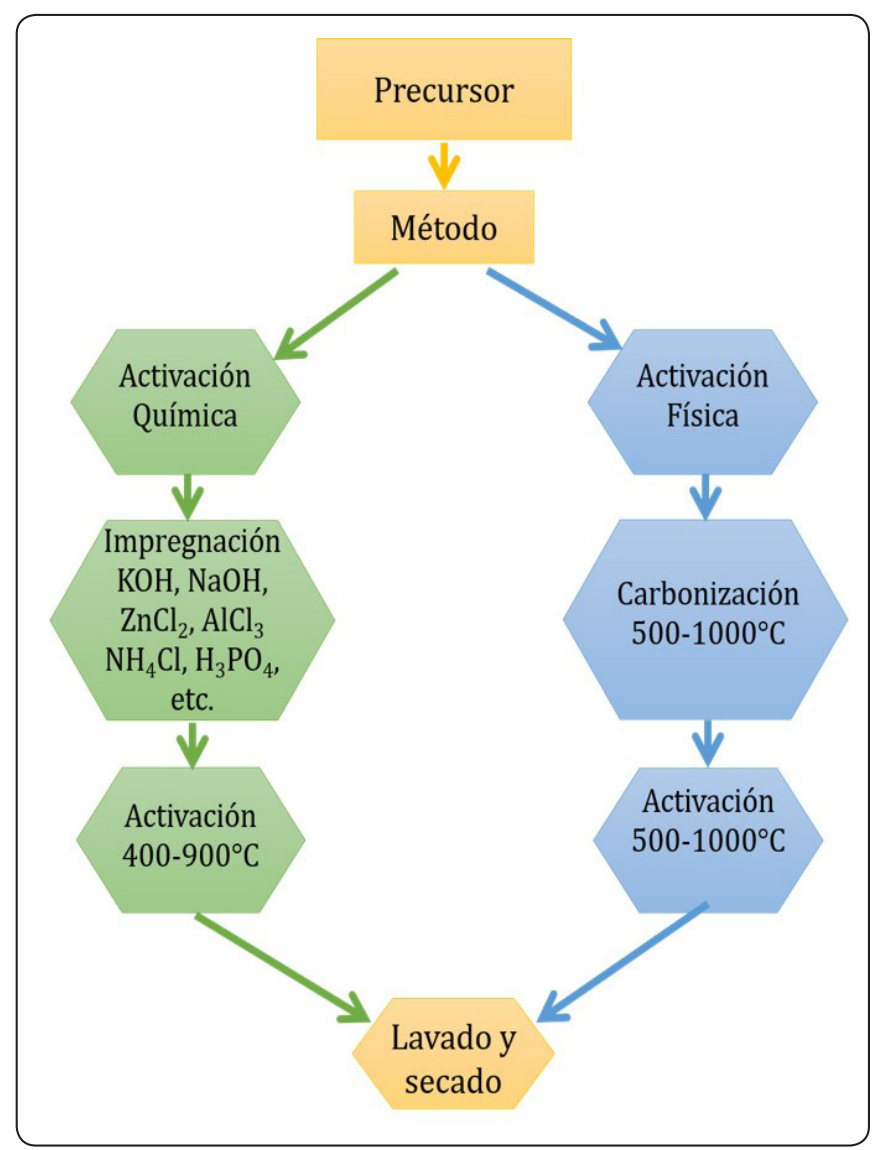

Figura 3. Esquema de comparación entre los diferentes métodos de activación Modificada de (Carrillo Quijano, 2013).

son impregnados con una clase de reactivos químicos cuya función principal es servir como deshidratante impidiendo al mismo tiempo la producción de alquitranes; entre los agentes impregnantes más utilizados se encuentran el $\mathrm{KOH}, \mathrm{H}_{3} \mathrm{PO}_{4}$, cloruros como el $\mathrm{ZnCl}_{2}, \mathrm{AlCl}_{3} \mathrm{NH}_{4} \mathrm{Cl}$ y los carbonatos como el $\mathrm{Na}_{2} \mathrm{CO}_{3}$ y $\mathrm{K}_{2} \mathrm{CO}_{3}$ (Rodríguez, Giraldo \& Moreno, 2007; Rodríguez, Giraldo \& Moreno, 2009). El uso de $\mathrm{H}_{3} \mathrm{PO}_{4}$ es uno de los métodos de activación más efectivos y menos costosos para la fabricación de materiales de carbón activado, para los que es más fácil llevar a cabo la activación a temperaturas inferiores a $500{ }^{\circ} \mathrm{C}$ y obtener productos de carbono con estructura mesoporosa (Duan, Srinivasakannan, Wang, Wang \& Liu, 2017).

En la Tabla I se muestran algunas de las ventajas y desventajas que presentan los métodos para la activación de las TCA; se observan mejores características en la activación química en comparación con la activación física; el rendimiento de carbono suele ser mayor con estructuras de poros mejor desarrollados, además, se requiere una temperatura de activación más baja que en el proceso de activación física (Duan, Srinivasakannan, Wang, Wang \& Liu, 2017). Sin embargo, el único inconveniente en la producción de estos materiales por el proceso de activación química son sus costos elevados; por lo cual al ser utilizado surge la necesidad de buscar precursores más económicos y fáciles de adquirir (Kordek, Yin, Rutkowski \& Zhao, 2018).

Duan, Srinivasakannan, Wang, Wang \& Liu. (2017) estudiaron la preparación de TCA asistida por microondas, utilizando algodón como precursor, con un tiempo de activación de 10 min y con una concentración de $\mathrm{H}_{3} \mathrm{PO}_{4}$ de $50 \%(\mathrm{p} / \mathrm{p})$. Cordero-Lanzac, García-Mateos, Rosas, Rodríguez-Mirasol \& Cordero (2018) obtuvieron TCA baratas a partir de residuos de tela de mezclilla por activación química con $\mathrm{H}_{3} \mathrm{PO}_{4}$; el carbón activado preparado a $900{ }^{\circ} \mathrm{C}$ con una relación de impregnación de $0.5\left(\mathrm{H}_{3} \mathrm{PO}_{4} /\right.$ tela de mezclilla) exhibe el mejor rendimiento como capacitor eléctrico de doble capa. El electrodo mostró una superficie con área específica de 2032 $\mathrm{m}^{2} / \mathrm{g}$ y la más alta capacitancia gravimétrica registrada (237 F/g). Por otro lado, Yoda, Shibuya \& Myoubudani (2018) prepararon TCA utilizando varias combinaciones de fibras de algodón y poliéster en diferentes condiciones de tratamiento térmico. Los resultados de los experimentos de adsorción de metileno revelaron que el tratamiento térmico es efectivo para preparar TCA derivados de mezclas de fibras que incluyen poliéster.

Las características y propiedades de las TCA dependen de la tela del material polimérico que se utiliza para producirla, el método de preparación y el proceso de activación. (Babic, Milonjic, Polovina, Cupic \& Kaludierovic, 2002; OcampoPérez et al., 2013). Estas características especiales han sido

\begin{tabular}{|l|l|l|}
\hline \multicolumn{1}{|c|}{ Método } & \multicolumn{1}{|c|}{ Ventajas } & \multicolumn{1}{c|}{ Desventajas } \\
\hline Activación Física & Bajo costo & $\begin{array}{l}\text { Requiere mayor temperatura }\left(800-1000{ }^{\circ} \mathrm{C}\right) . \\
\text { Requiere mayor tiempo de activación. }\end{array}$ \\
\hline Activación Química & $\begin{array}{l}\text { Proporciona altos rendimientos. } \\
\text { Se desarrolla a temperaturas de activación más } \\
\text { bajas }\left(400-800^{\circ} \mathrm{C}\right) .\end{array}$ & $\begin{array}{l}\text { Mayor costo. } \\
\text { Es necesario un lavado exhaustivo del } \\
\text { carbonizado resultante para eliminar residuos de } \\
\text { los activantes. }\end{array}$ \\
\hline
\end{tabular}

Tabla I. Ventajas y desventajas de los métodos para la activación de materiales carbonosos. 
aprovechadas en una gran cantidad de aplicaciones en la vida moderna e incluso entrando en nuevos campos de la ciencia gracias a las nuevas investigaciones. Dentro de estas aplicaciones se encuentra el uso de las TCA en la operación de sistemas de aire acondicionado, en la creación de equipos de protección personal (trajes, máscaras, y filtros que no permiten el contacto de agentes tóxicos o radioactivo con las personas al encapsular los compuestos) (Estévez Mujica, MorenoPirajan, \& Vargas, 2006), su uso como sistemas de soporte de catalizadores (Rodríguez, Giraldo \& Moreno, 2007), en la industria se usa para la adsorción de contaminantes (Costa, Alves, Azevedo \& Bastos, 2017), purificación de aguas (Cao et al., 2017), tratamiento de aguas residuales (Leyva Ramos, Díaz Flores, Guerrero Coronado, Mendoza Barrón \& Aragón Piña, 2004; Giraldo \& Moreno, 2004), en el almacenamiento de gases y en aplicaciones biomédicas para el tratamiento de envenenamientos y sobredosis (Fernández, Bonastre, Molina, del Río \& Cases, 2017; Coplas, Tarón \& González, 2017; Gineys, Benoit, Cohaut, Béguin \& Delpeux-Ouldriane, 2017).

\section{Aplicaciones \\ Uso de TCA en la purificación y el tratamiento de aguas residuales}

Numerosos estudios han demostrado que una gran variedad de contaminantes se detecta con frecuencia en el agua en pequeñas concentraciones que van desde $\mathrm{ng} / \mathrm{L}$ a $\mu \mathrm{g} / \mathrm{L}$. Estos contaminantes son un tema de preocupación emergente en el tratamiento de aguas residuales industriales y municipales, en la protección ambiental y en la producción de agua potable (Nieto-Delgado, Partida-Gutiérrez \& Rangel Méndez, 2019). Debido a que han incrementado su nivel en la contaminación y presentan un riesgo para la salud humana, es necesario la investigación y el desarrollo de métodos más efectivos para su eliminación (Masson et al., 2016). En las últimas décadas, los materiales a base de carbono, como las TCA, se usan ampliamente para descontaminar el agua de materiales orgánicos e inorgánicos debido a su alta capacidad de adsorción y no toxicidad (Matovic et al., 2016; Gineys, Benoit, Cohaut, Béguin \& Delpeux-Ouldriane, 2016). La capacidad de adsorción de un carbón activado depende de las propiedades de su textura, las propiedades químicas de la superficie, la naturaleza del adsorbente utilizado, así como la naturaleza y la concentración del adsorbato y el pH de la solución (Kumita et al., 2018; Blanco, Giraldo \& Moreno, 2007; Babic, Milonjic, Polovina, Cupic \& Kaludierovic, 2002). Las TCA son adsorbentes porosas y versátiles utilizadas tanto para el tratamiento de aguas contaminadas como para remover colorantes, tricloroetileno, fenoles, cianuros, butano, sulfuro de hidrógeno, haluros orgánicos y muchos otros compuestos, así como su uso en la remoción de VOCs (benceno, acetona, diclorometano, n-hexano, acrilonitrilo, etc.) y la remoción de metales pesados (antimonio, arsénico, berilio, cadmio, cromo, cobre, plomo, mercurio, níquel, selenio, plata, talio y zinc) (Rodríguez, Giraldo \& Moreno, 2009). Rangel-
Méndez \& Streat., (2002) oxidaron TCA basadas en fibra de poliacrilonitrilo (PAN) utilizando $\mathrm{HNO}_{3}$, ozono y oxidación electroquímica, demostrando que las TCA oxidadas tienen un potencial considerable como adsorbentes para la eliminación a gran escala de contaminantes del agua a valores de $\mathrm{pH}$ neutros o casi neutros. Mientras que, Huang \& Su (2010) también utilizaron una tela basada en PAN modificándola con $\mathrm{HNO}_{3}$ y la impregnaron con quitosano para analizar y comprender mejor el mecanismo de adsorción/electrosorción; demostrando que la capacidad de electrosorción es significativamente mayor que la capacidad de adsorción. En la Figura 4 se muestra un estudio realizado por (Kostoglou et al., 2017), donde utilizaron como precursor de carbono una tela de rayón viscosa de color blanquecino (Figura 4a), que prepararon mediante impregnación química en una mezcla acuosa de catalizadores de $\mathrm{ZnCl}_{2}$ y $\mathrm{NH}_{4} \mathrm{Cl}$, seguida de una carbonización en $\mathrm{N}_{2}$ y una activación en $\mathrm{CO}_{2}$, para obtener una TCA nanoporosa y flexible (Figura 4b). Los resultados de esta síntesis se pueden observar en la Figura 4c y 4d, la cual muestra imágenes de SEM de la estructura jerárquica de las TCA en una amplia gama de aumentos que cubre órdenes de magnitud que van desde $\mathrm{mm}$ a $\mu \mathrm{m}$.

En la Tabla II se muestra la comparación de algunos estudios realizados por diversos investigadores, utilizando FCA y TCA como materiales adsorbentes para la remoción de contaminantes de soluciones acuosas; cada material muestra una capacidad de adsorción diferente según las condiciones utilizadas para cada investigación. La máxima capacidad de adsorción registrada es de las TCA modificadas con $\mathrm{NH}_{3}$, $\mathrm{K}_{2} \mathrm{~S}_{2} \mathrm{O}_{8}$ y $\mathrm{O}_{3}$, utilizadas para la adsorción de nitromidazoles.

\section{Uso de TCA como electrodo para desionización}

El tratamiento de desalinización del agua se considera uno de los grandes desafíos tecnológicos del siglo XXI. Para lograr este objetivo, se han desarrollado procesos de desalinización, como la ósmosis inversa, la electrodiálisis y la destilación instantánea multietapa. Recientemente, la desionización (DI) ha ganado mucha atención como una tecnología de desalinización de aguas subterráneas debido a sus ventajas de bajo consumo de energía, alta eficiencia energética, y compatibilidad ambiental (Chen, Cheng \& Wang, 2018; Kim, Srimuk, Lee \& Fleischmann, 2017; Min, Choi, \& Jung, 2018). La DI es un nuevo proceso eficiente y económico para eliminar la sal y las impurezas del agua (Oh et al., 2006; Zhang, He, Ma, Tang \& Waite, 2018) utilizando como material de electrodo: los carbones activados, aerogeles de carbono, telas de carbón, grafeno, nanotubos de carbón, compuestos a base de carbono (Li et al., 2017), principalmente los carbonos mesoporosos y los carbonos porosos jerárquicos (Baroud \& Giannelis, 2018). El método de DI, basado en el modelo eléctrico de doble capa, funciona con un potencial de carga directa (CD) bajo que va desde 1.0 a $1.2 \mathrm{~V}$ para evitar reacciones electroquímicas en las superficies de los electrodos (Myint, Al-Harthi \& Dutta, 2014). 


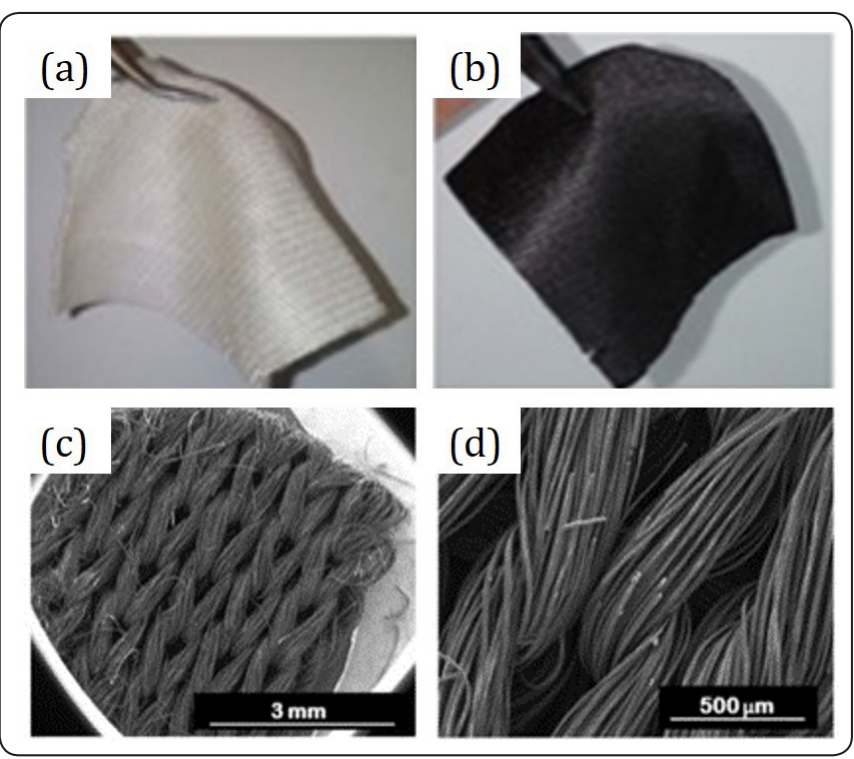

Figura 4. (a) precursor de tela de rayón viscosa, (b) tela de carbón nanoporosa; imágenes de SEM a diferentes aumentos mostrando (c) TCA y (d) hilos tejidos Modificada de (Kostoglou et al., 2017).

En la tecnología de la DI las propiedades de la superficie del electrodo desempeñan un papel vital en términos de área de la superficie, estructura micro/mesoporosa, distribución del tamaño de los poros, grupos funcionales en la superficie del electrodo y adsorción o desorción del ion en la superficie (Myint \& Dutta, 2012). La superficie de la tela de carbono que ha activado a través de la ruta química y la ruta electroquímica, han demostrado mejorar significativamente las propiedades adsorbentes y electroquímicas. Sin embargo, la activación de la tela de carbón por el método químico ha facilitado una mayor eficiencia del electrodo en el proceso de DI (Thamiselvan et al., 2018; Ahn et al., 2007). Algunos de los materiales semiconductores aplicados para modificar los electrodos de las células de DI son óxidos metálicos como $\mathrm{ZnO}, \mathrm{TiO}_{2}$ y $\mathrm{MnO}_{2}$ (Myint, Al-Harthi \& Dutta, 2014). En la construcción de células de DI convencionales, normalmente se utiliza un canal de malla abierta entre un par de electrodos porosos para el flujo de agua y para evitar cortocircuitos. El funcionamiento de la célula de DI se basa en la electroadición/ desorción reversible de iones en la interfaz electrodo/ electrolito (Kim, Srimuk, Lee \& Fleischmann, 2017). La adsorción de iones en una superficie de carbono se clasifica como adsorción física y electrosorción: la adsorción física se produce debido a la interacción entre los grupos polares de la superficie del carbono y los iones, y la electrosorción se debe a la atracción entre la superficie del electrodo cargado y los iones. La eliminación de iones por DI se basa en la electrosorción, pero la adsorción física reduce la eficiencia de DI al mantener iones en la superficie durante la etapa de regeneración. Por lo tanto, una disminución en la adsorción física con un aumento en la electrosorción es una forma prometedora de mejorar el rendimiento de la DI (Ryoo, Kim \& Seo, 2003). En la Figura 5 se observa un diagrama esquemático de un sistema DI convencional que muestra el paso de la desionizacion/desalinización (Figura 5a) y el paso de la regeneración de electrodos (Figura 5b); este sistema consiste en dos electrodos altamente porosos, con un separador en medio; los materiales de los electrodos son típicamente a base de carbono, y el agua de alimentación fluye entre o a través de los electrodos de carga según el diseño de instalación (Oladunni et al., 2018).

\begin{tabular}{|c|c|c|c|c|}
\hline Descripción & $\begin{array}{l}\text { Precursor } \\
\text { utilizado }\end{array}$ & $\begin{array}{c}\text { Capacidad } \\
\text { de adsorción } \\
(\mathrm{mg} / \mathrm{g})\end{array}$ & Aplicación & Referencia \\
\hline FCA oxidadas con persulfato de amonio & $* \mathrm{NA}$ & 559 & Remoción de $\mathrm{Pb}$ & $\begin{array}{l}\text { Mena Aguilar, Amano \& } \\
\text { Machida (2016) }\end{array}$ \\
\hline FCA activadas con $\mathrm{H}_{3} \mathrm{PO}_{4}$ & algodón & 476 & Adsorción de MB & $\begin{array}{l}\text { Duan, Srinivasakannan, } \\
\text { Wang, Wang \& Liu } \\
\text { (2017) }\end{array}$ \\
\hline FCA activadas térmicamente con $\mathrm{H}_{2} \mathrm{SO}_{4}$ & $\begin{array}{l}\text { cáscara de } \\
\text { coco }\end{array}$ & 12.2 & $\begin{array}{l}\text { Descontaminación de } \\
\text { cromo trivalente }\end{array}$ & $\begin{array}{l}\text { Mohan, Singh \& Singh } \\
(2006)\end{array}$ \\
\hline TCA activadas térmicamente con $\mathrm{H}_{2} \mathrm{SO}_{4}$ & $* \mathrm{NA}$ & 39.56 & & \\
\hline TCA modificadas con $\mathrm{NH}_{3}, \mathrm{~K}_{2} \mathrm{~S}_{2} \mathrm{O}_{8}$ y $\mathrm{O}_{3}$ & *NA & 500 & $\begin{array}{l}\text { Adsorción de } \\
\text { nitromidazol (MNZ) }\end{array}$ & $\begin{array}{l}\text { Ocampo-Pérez et al. } \\
\text { (2013) }\end{array}$ \\
\hline TCA modificadas con $\mathrm{NH}_{3}, \mathrm{~K}_{2} \mathrm{~S}_{2} \mathrm{O}_{8}$ y $\mathrm{O}_{3}$ & $* \mathrm{NA}$ & 600 & $\begin{array}{l}\text { Adsorción de } \\
\text { nitromidazol (DMZ) }\end{array}$ & \\
\hline TCA mejoradas químicamente & rayón viscosa & 5.3 & Remoción de arsénico & Matovic et al. (2016) \\
\hline
\end{tabular}

Tabla II. Capacidad de adsorción de diferentes FCA y TCA. 
Myint, Al-Harthi \& Dutta (2014) fabricaron micro/ nanoestrucutras de $\mathrm{ZnO}$ que cultivaron hidrotérmicamente en TCA para utilizarlas como electrodos en una celda de flujo para la desalinización de agua salobre, logrando una eficiencia de eliminación de sal del 22\% y una capacidad de adsorción de sal de $8.5 \mathrm{mg} / \mathrm{g}$. Mientras que, Laxman et al. (2015) diseñaron un prototipo de una celda de DI usando TCA como electrodo (Figura 6) para la desalinización de agua salobre y agua sintética $(\mathrm{NaCl})$, logrando una eficiencia de desalinización para el agua sintética de $32 \%$ y para el agua salobre de $27 \%$, con una capacidad de adsorción de sal de $10.5 \mathrm{mg} / \mathrm{g}$ y $8.9 \mathrm{mg} / \mathrm{g}$ respectivamente.

\section{Uso de TCA como supercapacitores flexibles}

A lo largo de las décadas, los dispositivos de almacenamiento de energía de alto rendimiento se han convertido en el foco de atención de la sociedad debido a sus fuertes demandas. Hasta la fecha se han desarrollado muchos tipos de dispositivos de almacenamiento de energía, que incluyen supercapacitores (SC), baterías de flujo redox, baterías de ion zinc, baterías de ion $\mathrm{Li} / \mathrm{Na}$ (LIBs/NIBs), baterías $\mathrm{Li} / \mathrm{Na}-\mathrm{S}$, baterías metal-aire, etc. (Chen et al., 2018). Los capacitores eléctricos de doble capa (CEDC) o supercapacitores (SC) son dispositivos de almacenamiento rápido de energía, cuyo mecanismo consiste en la acumulación de cargas en la doble capa generada en la interfase entre electrodo y el electrolito (Cordero-Lanzac, García-Mateos, Rosas, Rodríguez-Mirasol \& Cordero, 2018). Los SC han atraído una gran atención por sus excelentes características, como alta densidad de potencia, altas velocidades de carga y descarga, el ciclo de vida prolongado y la buena seguridad. Sus densidades de energía (típicamente 4-5 $\mathrm{W} \mathrm{h} / \mathrm{Kg}$ ) están determinadas por el área de superficie electroactiva y la distribución del tamaño de los poros de los materiales de carbono (Wang et al., 2017). Los SC han sido utilizados ampliamente en aplicaciones comerciales que van desde pequeños dispositivos electrónicos como teléfonos

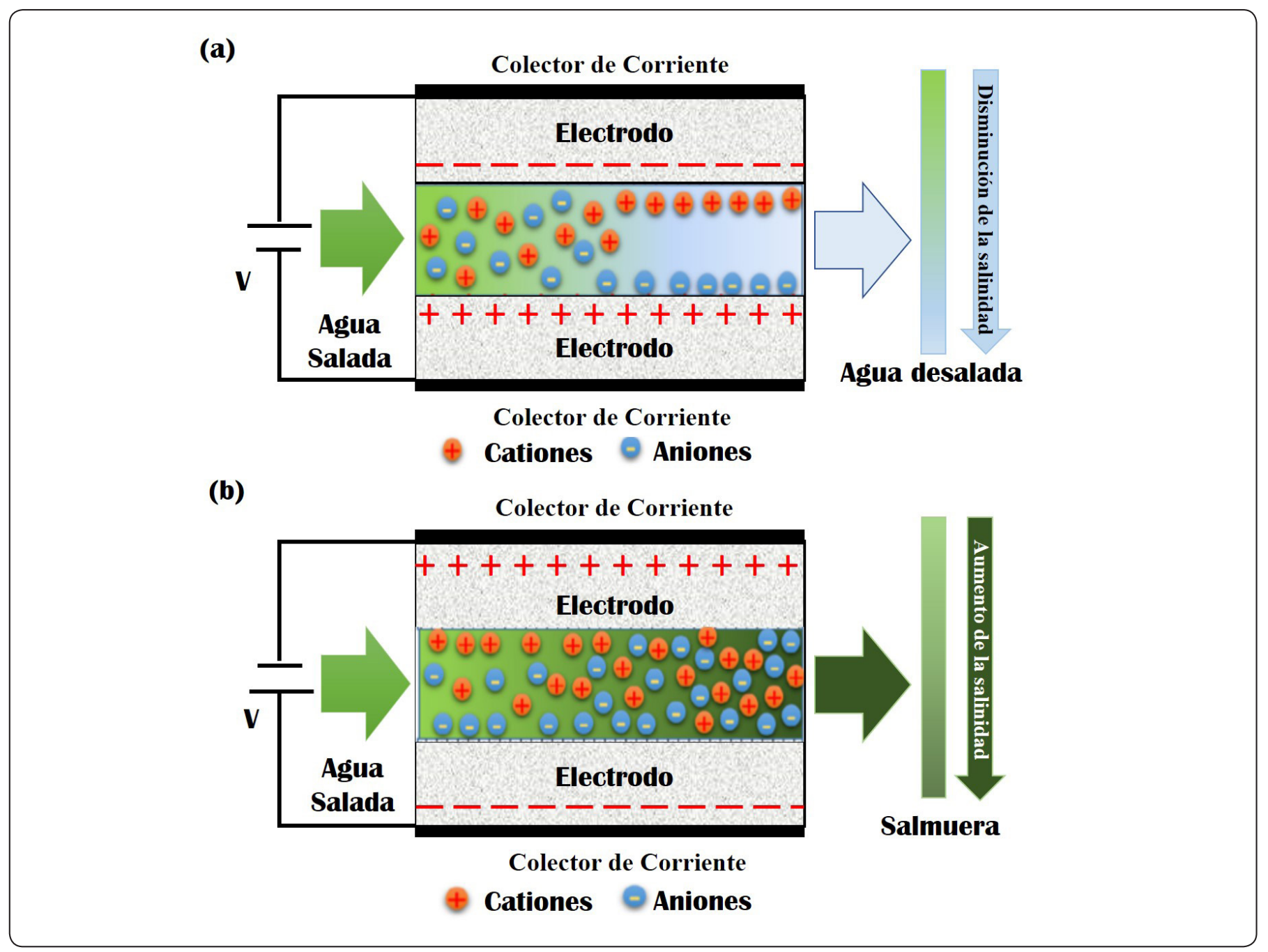

Figura 5. Diagrama esquemático de un sistema de DI convencional; (a) Desionización/desalinización y (b) regeneración de electrodos Modificada de (Oladunni et al., 2018). 


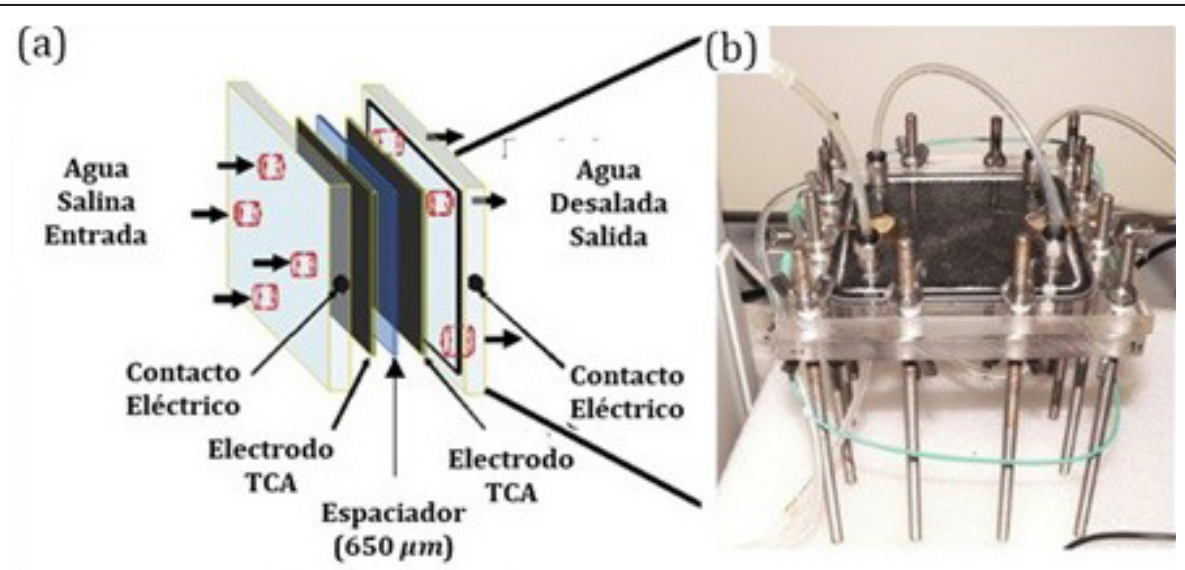

Figura 6. (a) Representación esquemática de la célula de DI que consta de dos electrodos hechos de tela de carbón activado separados por un espaciador hecho de papel filtro (650 ) y (b) prototipo de la célula de DI compuesta de electrodos de TCA de $100 \mathrm{~cm}^{2}$ trabajando a un potencial aplicado de 1.6 V de CD. Modificada de (Laxman et al., 2015).

celulares, aparatos de emergencia para vehículos eléctricos, células fotovoltaicas, sistema de energía de respaldo, etc. (Ling et al., 2018). Los materiales de carbón en polvo son muy atractivos para el almacenamiento de energía debido a su alta porosidad, buena conductividad eléctrica y notable estabilidad química en diversas soluciones electrolíticas. Además, el uso de carbón activado en forma de tela proporciona beneficios adicionales como la flexibilidad, evitar el uso de cualquier aglomerante y la alta densidad, lo que puede ser útil para producir capacitores compactos. (Sieben, Morallón \& Cazorla-Amorós, 2013). Las TCA flexibles y conductoras se han utilizado ampliamente para construir electrodos textiles de alto rendimiento combinadas con materiales que tienen propiedades parecidas a un capacitor como, $\mathrm{ZnCo}_{2} \mathrm{O}_{4}, \mathrm{MnO}_{2}, \mathrm{Fe}_{2} \mathrm{O}_{3}, \mathrm{Co}_{3} \mathrm{O}_{4}$ o $\mathrm{V}_{2} \mathrm{O}_{5}$ (Jeon et al., 2018).

En la Figura 7 se muestran algunos de los procesos utilizados por diferentes investigadores para la preparación de tela de carbón recubierta con diferentes tipos de materiales; Feng, Li, Zhang \& Zhang (2017) descubrieron la producción de telas de carbono recubiertas con nano-hojas de $\mathrm{MnO}_{2}$ (TC/ $\mathrm{MnO}_{2}$ ) o telas de carbono recubiertas con nanobarras de $\mathrm{MnOOH}(\mathrm{TC} / \mathrm{MnOOH}$ ) como electrodos (Figura 7a); Chen et al. (2018) informaron sobre el crecimiento in situ de nanohojas de $\mathrm{MoS}_{2}$ recubiertas con carbón sobre un sustrato de tela de carbono utilizando una reacción hidrotérmica seguida de una calcinación (Figura 7b). Por otro lado, Ling et al. (2018) informaron sobre la fácil fabricación de un nuevo compuesto que consiste en polianilina, trióxido de molibdeno y TCA (PANI/MoO $/$ TCA) como un material de electrodo para supercapacitores (Figura 7c). Los resultados obtenidos de los estudios mencionados anteriormente se pueden observar en la Tabla III, que muestran la comparación del valor de la capacitancia específica para cada uno de los compuestos realizados. PANI/ $\mathrm{MoO}_{3} / \mathrm{TCA}$ exhibe una capacitancia especifica de $1050 \mathrm{~F} / \mathrm{g}$, significativamente mayor que la de los compuestos realizados por Feng, Li, Zhang \& Zhang (2017).

\section{Uso de TCA como soporte catalítico}

Las celdas de combustible microbianas (CCM) pueden degradar los contaminantes orgánicos y al mismo tiempo cosechar electricidad de las aguas residuales, lo que representa una de las tecnologías más prometedoras para el reciclaje de desechos. Los metales como el platino se han utilizado durante mucho tiempo como excelentes catalizadores para superar el elevado sobrepotencial y la pobre cinética de la reacción de reducción de oxígeno en medio neutro. Sin embargo, los recursos limitados, el alto costo y la sensibilidad al envenenamiento por diversos productos químicos impiden la aplicación práctica de estos metales. Por lo tanto, el

\begin{tabular}{|c|c|c|}
\hline Autor & Compuesto & $\begin{array}{c}\text { Capacitancia } \\
\text { Específica }(\mathrm{C}) \\
(\mathrm{F} / \mathrm{g})\end{array}$ \\
\hline \multirow{2}{*}{$\begin{array}{l}\text { Feng, Li, Zhang } \\
\text { \& Zhang, (2017) }\end{array}$} & $\mathrm{TC} / \mathrm{MnO}_{2}$ & 429.2 \\
\hline & $\mathrm{TC} / \mathrm{MnOOH}$ & SD \\
\hline $\begin{array}{l}\text { Chen et al. } \\
\text { (2018) }\end{array}$ & $\begin{array}{l}\text { Nano-hojas de } \\
\mathrm{MoS}_{2}\end{array}$ & SD \\
\hline \multirow{3}{*}{ Ling et al. (2018) } & PANI/TC & 500 \\
\hline & $\mathrm{MoO}_{3} / \mathrm{TCA}$ & 296.7 \\
\hline & $\mathrm{PANI} / \mathrm{MoO}_{3} / \mathrm{TCA}$ & 1050 \\
\hline
\end{tabular}

Tabla III. Comparación de la capacitancia específica en diferentes estudios realizados. 


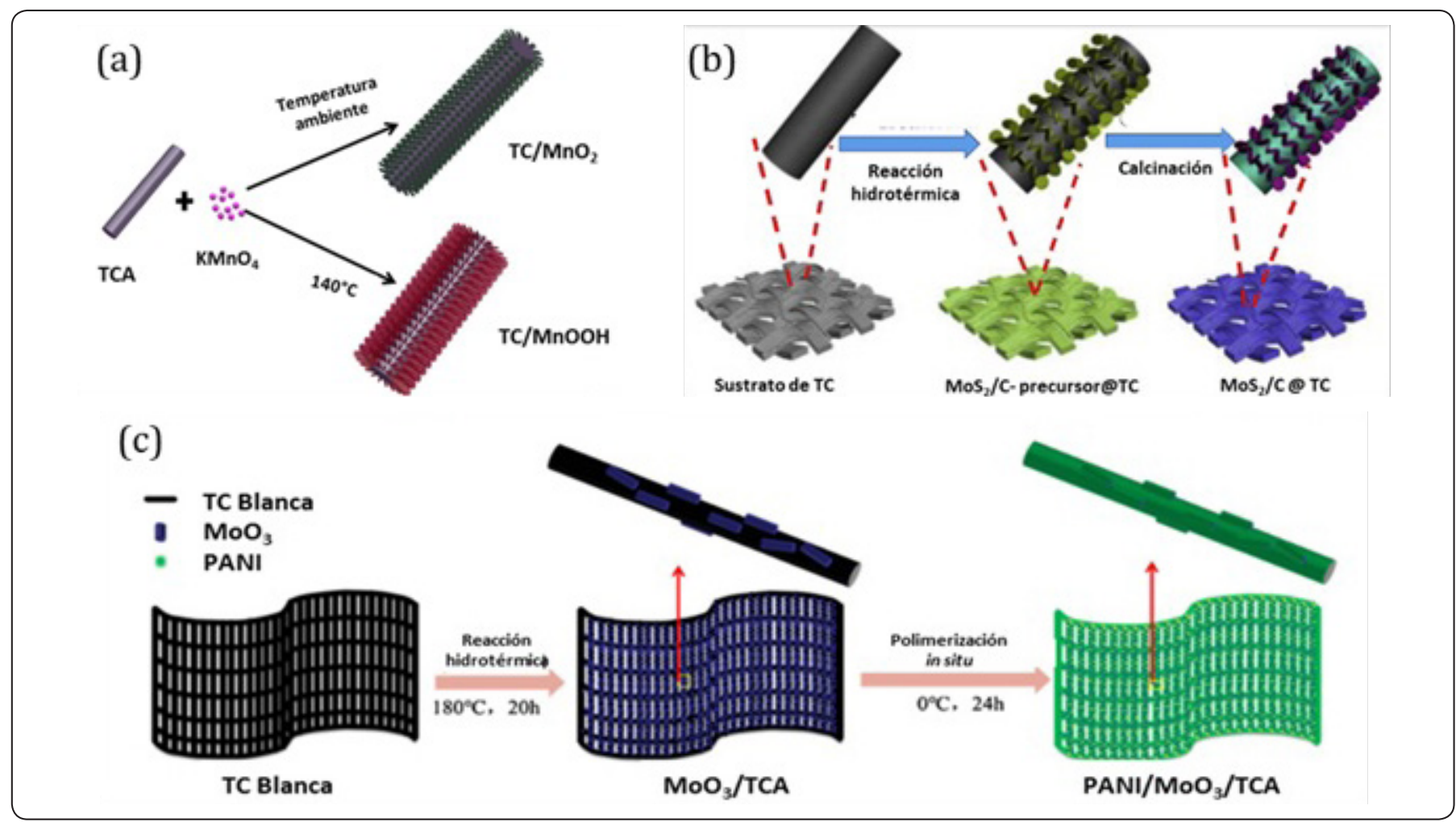

Figura 7. Pasos para la preparación de materiales compuestos analizados por diferentes investigadores: (a) Síntesis de TC/MnO $\mathrm{TC}_{2}$ MnOOH (Feng, Li, Zhang \& Zhang, 2017), (b) Síntesis de MoS $/$ C@CC (Chen, Cheng \& Wang, 2018) y (c) Síntesis de PANI/MoO,/TCA (Ling et al., 2018). Modificada de los autores citados.

desarrollo de electrocatalizadores de reacción de reducción de oxígeno alternativos con alta actividad y bajo costo es de gran importancia para la aplicación práctica de las CCM (Liu, Fan \& Liu, 2019). Un enfoque sugerido es soportar los catalizadores en materiales con grandes áreas de superficie como carbón activado, nanofibras de carbono, nanotubos de carbono y grafeno (Ghiabi, Ghaffarinejad, Kazemi \& Salahandish, 2018). Uno de los materiales alternativos que está siendo investigado como soporte de catalizadores para procesos de hidrotratamiento es el carbón activado (Robles Andrade et al., 2006); los carbones activados usados en catálisis presentan un volumen específico de poro entre 0.9 y $1.3 \mathrm{~mL} / \mathrm{g}$ y áreas superficiales entre 800 y $1200 \mathrm{~m}^{2} / \mathrm{g}$. La gran ventaja del uso de carbones activados como soporte catalítico, además de su bajo costo, es la idea de obtener grandes dispersiones de fases inorgánicas, haciendo más eficiente su uso, al maximizar el área expuesta de las mismas (Ospina-Guarín, Buitrago-Sierra \& López-López, 2014). Las formas texturales de materiales de carbón activado, como TCA y fieltros de carbón activado, representan características ventajosas notables con respecto a los carbones activados granulares habituales. La TCA es una tela barata altamente conductora que se puede aplicar ampliamente como soporte para electrocatalizadores (Kordek, Yin, Rutkowski \& Zhao, 2018). Debido a la elasticidad mecánica y la flexibilidad geométrica, las telas de fibra pueden doblarse y enrollarse fácilmente para adaptarse a usos particulares. Las telas tejidas con fibras delgadas reducen la distancia de difusión y producen una caída de baja presión en lechos fijos y en reactores multifásicos en los que una o más especies disueltas tienen que reaccionar con compuestos gaseosos de solubilidad limitada. El catalizador de TCA es una alternativa atractiva porque puede reemplazarse rápida y fácilmente cuando sea necesario (Gudarzi, Ratchananusorn, Turunen, Heinonen \& Salmi, 2015).

Wei et al. (2017) prepararon un catalizador Co-Mo-B, similar al diente de león, soportado en una TCA mediante el método de electrodeposición para la regeneración de hidrógeno a partir de una solución alcalina de $\mathrm{NaBH}_{4}$ (Figura 8); observaron que el catalizador exhibía una alta tasa de generación de hidrógeno y una baja energía de activación para la hidrólisis de soluciones alcalinas de $\mathrm{NaBH}_{4}$. Kordek, Yin, Rutkowski \& Zhao (2018), utilizaron una técnica simple de electrodeposición en un solo paso para cultivar directamente películas mixtas basadas en Co sobre una superficie de TCA electroquímicamente, demostrando que mejora significativamente la actividad electrocatalítica de las películas mixtas como resultado de la activación electroquímica de la TCA antes de la electrodeposición del material. Por otro lado, Zou et al. (2019) prepararon un compuesto de $\mathrm{MnO}_{2}$ soportado en 
TC $\left(\mathrm{TC}-\mathrm{MnO}_{2}\right)$ para determinar la oxidación catalítica del formaldehído gaseoso (HCHO) con la ayuda de energía eléctrica; en el que observaron que el compuesto (TC- $\mathrm{MnO}_{2}$ ) exhibía propiedades únicas de calor Joule y podría convertir eficientemente la energía eléctrica en energía térmica.

\section{Uso de TCA en el almacenamiento de gases}

El uso excesivo de combustibles fósiles como fuente principal de energía se ha convertido en una de las causas más importantes de contaminación ambiental debido a las emisiones de gases como $\mathrm{CO}_{2}, \mathrm{CO}$, hidrocarburos, $\mathrm{SO}_{2}, \mathrm{NOx}$, compuestos orgánicos volátiles (VOC) y material particulado, los cuales son causantes del efecto invernadero, lluvia ácida, smog fotoquímico, disminución del ozono estratosférico, calentamiento global, y grandes efectos sobre la salud humana debido a la alta toxicidad de estas sustancias que son emitidas a la atmósfera (López, Hoyos \& Mondragón, 2011). Para reducir estas emisiones, se han realizado técnicas para la captura y el almacenamiento de gases utilizando la adsorción en materiales sólidos. Actualmente numerosos estudios van encaminados a determinar qué materiales resultan más convenientes para el proceso de adsorción, encontrándose entre los más estudiados los nanotubos de carbón, las nanofibras de carbón y los carbones activados (TCA) (Hernández, Jiménez, Mondragón \& López, 2007). Las TCA con su estructura porosa y tridimensionalmente conectada, son prometedoras para la preparación de telas multifuncionales debido a su conductividad eléctrica y térmica, su flexibilidad y su ligereza (Zou et al., 2019). Además, las propiedades únicas de adsorción y la estructura de la tela los convierte en materiales ideales para el confinamiento y almacenamiento de portadores de energía altamente densos, como el hidrógeno (Sevilla, Fuertes \& Mokaya, 2011) y metano $\left(\mathrm{CH}_{4}\right)$ (LozanoCastello, Alcaniz-Monge, De la Casa-Lillo, Cazorla-Amorós \& Linares-Solano, 2002), captura y separación de emisiones de gases de efecto invernadero no deseadas, como el dióxido de carbono $\left(\mathrm{CO}_{2}\right)$ (Adeniran \& Mokaya, 2015). En la Tabla IV se muestran algunos de los estudios realizados para la captura y el almacenamiento de gases; en ella se puede observar el área superficial y el volumen de poro de cada uno de los materiales, así como sus diferentes aplicaciones.

\section{Uso de la TCA en medicina}

El carbono, en todas sus formas (materiales carbonosos), ha demostrado ser excepcionalmente biocompatible con el hueso vivo y otros tejidos y, por lo tanto, está bien aceptado por el entorno biológico (Hong-mei, Phillips, Mikhalovsky \& Lloy, 2008). Las TCA están compuestas de fibras que son de diámetro pequeño, extremadamente porosas y con un área de superficie alta. Recientemente, se han usado en aplicaciones biomédicas debido a su buena compatibilidad biológica (Gineys, Benoit, Cohaut, Béguin \& Delpeux-Ouldriane, 2017). Dentro de estas aplicaciones se encuentra el uso de TCA para la protección de heridas por medio de vendas semipermeables que no permiten la entrada de microorganismos, que aíslan térmicamente la herida y adsorben los malos olores. (Estévez Mujica, Moreno-Pirajan, \& Vargas, 2006). Lin, Hsu, Chung, Ko \& Lin (2014) investigaron varias FCA con contenido de plata para comprender la eficacia de un vendaje que contiene diferentes concentraciones de plata; los resultados mostraron buenos efectos antibacterianos y biocompatibilidad celular. El modelo de herida por escisión infectada indicó que, en comparación con la FCA que contiene plata, así como otros vendajes comerciales, ayudó a la cicatrización de la herida mediante la promoción de la granulación y la deposición de colágeno.

Debido a sus excelentes propiedades mecánicas, las FCA se han utilizado como refuerzos en materiales compuestos para proporcionarles una alta compresión y resistencia a la tracción, así como también rigidez (Canal \& Ginebra, 2011). Las TCA han demostrado ser un buen soporte para el crecimiento y

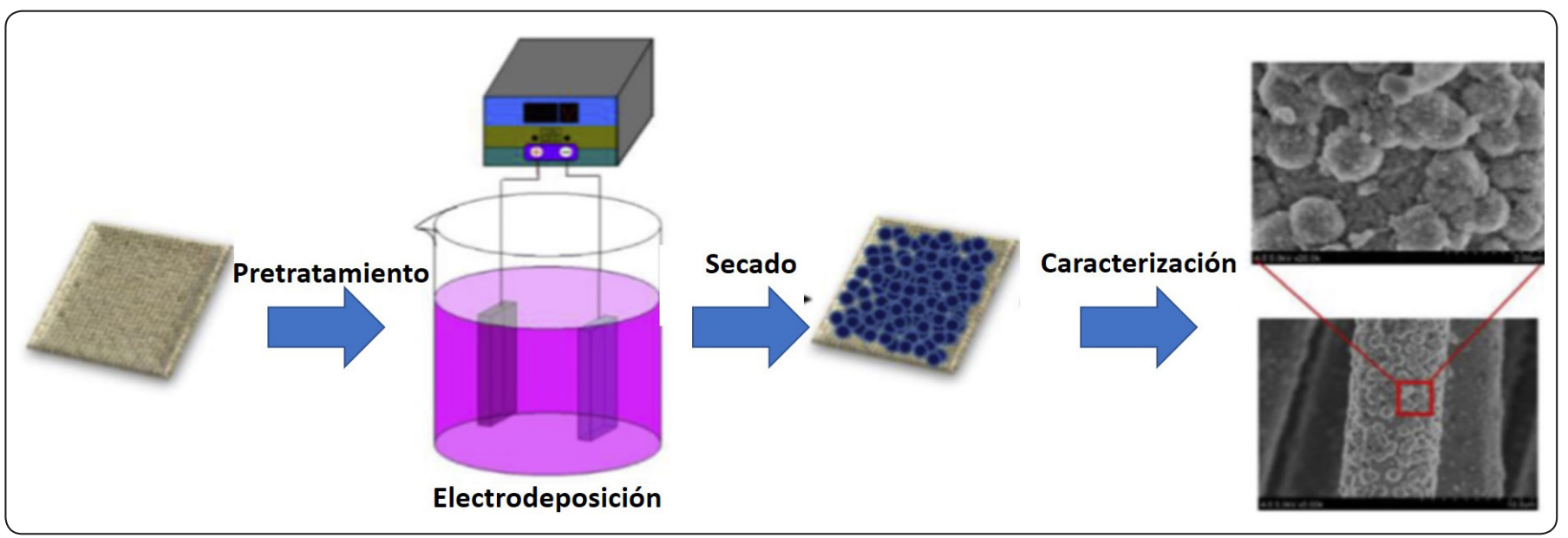

Figura 8. Diagrama esquemático simple del catalizador Co-Mo-B similar al diente de león electrodepositado en TCA Modificada de (Wei et al., 2017). 


\begin{tabular}{|c|c|c|c|c|}
\hline Material & $\begin{array}{c}\text { Área superficial } \\
\left(\mathrm{m}^{2} / \mathrm{g}\right)\end{array}$ & $\mathrm{V}_{\text {poro }}\left(\mathrm{cm}^{3} / \mathrm{g}\right)$ & Aplicación & Referencia \\
\hline TCA & $>1200$ & $\sim 0.5$ & $\begin{array}{l}\text { Almacenamiento de } \mathrm{H}_{2} \\
\text { Separación de mezclas } \mathrm{CO}_{2} / \mathrm{CH}_{4} \\
\text { Almacenamiento de energía electroquímica }\end{array}$ & $\begin{array}{l}\text { Kostoglou et al. } \\
\text { (2017) }\end{array}$ \\
\hline Telas de FCA & 995-2064 & $0.41-0.86$ & \multirow{3}{*}{ Conversión de NO } & \multirow{3}{*}{ Hu et al. (2019) } \\
\hline Zeolitas & $105-637$ & $0.065-0.44$ & & \\
\hline $\begin{array}{l}\text { Estructuras metálicas } \\
\text { orgánicas }\end{array}$ & $656-2375$ & $0.38-1.04$ & & \\
\hline $\begin{array}{l}\text { CA altamente } \\
\text { comprimido }\end{array}$ & 4000 & 3.00 & Almacenamiento de $\mathrm{H}_{2}$ y $\mathrm{CO}_{2}$ & $\begin{array}{l}\text { Adeniran \& } \\
\text { Mokaya (2015) }\end{array}$ \\
\hline
\end{tabular}

Tabla IV. Comparación y características de diferentes materiales utilizados para la captura y el almacenamiento de los gases.

diferenciación de células madre mesenquimales (CMM). Las CMM multipotenciales pueden originar un grupo limitado de tipos de células, que incluyen condrocitos, osteocitos, adipocitos, miocitos y neuronas. Se sabe que las células vivas se adhieren a la superficie del carbón activado por medio de la adsorción y este proceso puede explicarse mediante coloides y la química de superficie en términos de interacciones electrostáticas e hidrófobas. Las interacciones electrostáticas son muy dependientes de la solución de $\mathrm{pH}$, que afecta la carga de la superficie del carbono y la disociación o protonación de los grupos funcionales orgánicos de la membrana celular externa (López Peñalver et al., 2009). Los cementos de fosfato de calcio (CFC) pueden endurecerse in vivo, a través de una reacción de fraguado a baja temperatura. Los productos formados en esta reacción de fraguado tienen muchas similitudes con la fase mineral que constituye el $70 \%$ en peso del tejido óseo. Sin embargo, sus propiedades mecánicas están lejos de las del hueso cortical o incluso del hueso esponjoso. La incorporación de FCA al CFC no interfiere en la formación de cristales de hidroxiapatita durante el fraguado (Canal \& Ginebra, 2011) y las propiedades mecánicas del CFC podrían mejorarse significativamente al incorporar las fibras de carbón modificadas químicamente. La activación de la fibra tiene una fuerte influencia en la nucleación heterogénea de los cristales de fosfato de calcio en la superficie de la fibra y, en consecuencia, en la interfaz fibra-matriz (Boehm, Meininger, Tesch, Gbureck \& Müller, 2018). García-Ruiz \& Díaz Lantada, (2018) presentaron un enfoque innovador de múltiples materiales hacia el desarrollo sencillo, rápido y de bajo costo de andamios biomiméticos destinados a la reparación articular; el sistema se basa en la fabricación de estructuras de celosía tridimensionales diseñadas por computadora, en donde las FCA se tejen o se añaden posteriormente. Los andamios compuestos avanzados desarrollados, junto con la funcionalización del medio condicionado, constituyen nichos biomiméticos de células madre con potencial claro, no sólo para la formación de tendones y ligamentos, sino también para la formación de cartílago y endocondral ósea y estrategias de regeneración. Por otro lado, Hong-mei, Phillips, Mikhalovsky \& Lloy (2008) investigaron la interacción entre un rango de telas de carbono recubiertas con fosfato de calcio y células similares a osteoblastos humanos (MG63), para evaluar la biocompatibilidad de esta nueva gama de biomateriales; los resultados mostraron que la unión celular y la proliferación se mejoraron mediante el recubrimiento de tejidos de carbono con fosfato de calcio. Estas telas flexibles recubiertas con fosfato de calcio podrían, por lo tanto, tener usos en la reconstrucción del hueso en cirugía ortopédica y dental.

\section{Conclusiones}

Se compararon las diferentes formas de carbones activados, encontrando que las fibras de estos carbones son las que poseen mejores propiedades en comparación con las formas de carbón tradicional. Las fibras de carbón activado pueden presentarse tanto en tela como en fieltro. Sin embargo, las TCA han sido consideradas como un sustrato flexible prometedor debido a su bajo costo, su facilidad de manejo, su área de superficie alta, su integridad mecánica y su excelente conductividad. Para poder producir las TCA a partir de un precursor es necesario seguir una serie de pasos que incluyen, hilado, estabilización, carbonización y activación física o química; se observó que la activación química obtiene mayores ventajas en comparación con la activación física. Sin embargo, como tiene un costo elevado es necesario conseguir precursores más económicos para la fabricación de TCA. El agente activante más utilizado es el $\mathrm{H}_{3} \mathrm{PO}_{4}$, ya que es el más efectivo y menos costoso para la fabricación de materiales de carbón activado.

Estudios anteriores muestran que entre los diferentes materiales utilizados para la purificación y el tratamiento de aguas; las TCA modificadas con $\mathrm{NH}_{3}, \mathrm{~K}_{2} \mathrm{~S}_{2} \mathrm{O}_{8}$ y $\mathrm{O}_{3}$ exhibían la mejor capacidad de adsorción de $500-600 \mathrm{mg} / \mathrm{g}$, mostrando un potencial considerable para la adsorción de nitromidazoles. En los procesos de DI, la activación de la tela de carbón por el método químico ha mejorado la eficiencia del electrodo. Las micro/nanoestrucutras de $\mathrm{ZnO}$ estudiadas 
lograron una eliminación de sal del $22 \%$, mientras que el prototipo de la célula de DI conformada por dos electrodos de TCA lograron una eficiencia de desalinización de 32\% para el agua sintética y $27 \%$ para el agua salobre; su capacidad de adsorción fue de $8.5 \mathrm{mg} / \mathrm{g}$ para las micro/nanoestrucutras de $\mathrm{ZnO}$ y para el prototipo de la célula de DI fue $10.5 \mathrm{mg} / \mathrm{g}$ y $8.9 \mathrm{mg} / \mathrm{g}$, respectivamente. También se analizaron diferentes compuestos que son utilizados como supercapacitores. $\mathrm{PANI} / \mathrm{MoO}_{3} / \mathrm{TCA}$ exhiben una capacitancia (C) especifica de $1050 \mathrm{~F} / \mathrm{g}$, significativamente mayor que los compuestos de $\mathrm{MnO}_{2}, \mathrm{MnOOH}$ y $\mathrm{MoS}_{2}$. Por otra parte, el catalizador de TCA es una alternativa atractiva porque puede reemplazarse rápida y fácilmente cuando sea necesario, estudios anteriores muestran que los compuestos soportados sobre TCA para ser utilizados como catalizadores mejoran la actividad catalítica y podría convertir eficientemente la energía eléctrica en energía térmica. Las TCA son convenientes para la preparación de telas multifuncionales y las convierte en materiales ideales para el confinamiento y almacenamiento de gases. Las TCA con área superficial $>1200 \mathrm{~m}^{2} / \mathrm{g}$ y un volumen de poro de alrededor de $0.5 \mathrm{~cm}^{3} / \mathrm{g}$ son materiales versátiles para el almacenamiento de $\mathrm{H}_{2}$, la separación de $\mathrm{CO}_{2} / \mathrm{CH}_{4}$ y el almacenamiento de energía electroquímica.

Las TCA son ampliamente utilizadas en aplicaciones biomédicas debido a su buena biocompatibilidad y debido a sus excelentes propiedades mecánicas han demostrado ser un buen soporte para el crecimiento y diferenciación de células madre mesenquimales. La interacción entre TCA recubiertas con fosfato de calcio $(\mathrm{CaP})$ y células similares a osteoblastos humanos (MG63) mejoran la unión celular y la proliferación, por lo tanto, las TCA pueden usarse en la reconstrucción del hueso en cirugía ortopédica y dental.

\section{Agradecimientos}

Los autores agradecen a CONACYT-México la beca otorgada a Yohana Yazmín García Guelcon CVU (440931).

\section{REFERENCIAS}

Adeniran, B. \& Mokaya, R. (2015). Compactivation: a mechanochemical approach to carbons with superior porosity and exceptional performance for hydrogen and $\mathrm{CO}_{2}$ storage. Nano Energy, 16, 173-185. https://doi. org/10.1016/j.nanoen.2015.06.022

Ahn, H.J., Lee, J.H., Jeong, Y., Lee, J.H., Chi, Ch. S. \& Oh, H.J. (2007). Nanostructured carbon cloth electrode for desalination from aqueous solutions. Materials Science and Engineering A., 449, 841-845. https://doi:10.1016/j. msea.2006.02.448

Babic, B. M., Milonjic, S. K.,Polovina, M. J. \& Kaludierovic, B. V. (1999). Point of zero charge and intrinsic equilibrium constants of activated carbon cloth. Carbon, 37, 477-481. https://doi.org/10.1016/S0008-6223(98)00216-4

Babic, B. M., Milonjic, S. K., Polovina, M. J., Cupic, S. \&
Kaludierovic, B. V. (2002). Adsorption of zinc, cadmium and mercuryions from aqueous solutions on an activated carbon cloth. Carbon, 40, 1109-1115. https://doi. org/10.1016/S0008-6223(01)00256-1

Baroud, T.N. \& Giannelis, E.P. (2018). High salt capacity and hig removal rate capacitive deionization enabled by hierarchicalporous carbons. Carbon, 139, 614-625. https://doi.org/10.1016/j.carbon.2018.05.053

Blanco, D.A., Giraldo, L. \& Moreno, J. C. (2007). Adsorción de resorcinol desde solución acuosa sobre carbón activado. Revista Energética, 38, 73-77.https:// DOI: 10.15446/rev. colomb.quim

Boehm, A. V., Meininger, S., Tesch, A., Gbureck, U. \& Müller, F. A. (2018). The Mechanical Properties of Biocompatible Apatite Bone Cement Reinforced with Chemically Activated Carbon Fibers. Materials, 11(192), 1-12. https://doi.org/10.3390/ma11020192

Caglayan, B. \& Aksoylu, B. (2013). $\mathrm{CO}_{2}$ adsorption on chemically modified activated carbon. J. Hazard. Mater. 252,19-28.https://doi.org/10.1016/j.jhazmat.2013.02.028

Canal, C. \& Ginebra, M.P. (2011). Fibre-reinforced calcium phosphate cements: A review. Journal of the Mechanical Behavior of Biomedical Materials, 4(8), 1658-1671. https://doi.org/10.1016/j.jmbbm.2011.06.023

Cao, Y., Wang, K., Wang, X., Gu, Z., Ambrico, T., Gibbons, W., Fand, Q. \& Talukder, T. (2017). Preparation of active carbons from corns talk for butanol vapor adsorption. Journal of Energy Chemistry, 26, 35-41. https://dx.doi. org/10.1016/j.jechem.2016.08.009.

Carrillo Quijano, C. C., (2013). Producción de carbón activado y sílice a partir de cascarilla de arroz - una revisión. Scientia Et Technica, 18(2), 422-429.http:// dx.doi.org/10.22517/23447214.7855

Chen, N., Han, C., Shi, R., Xu, L., Li, H., Liu, Y., Li, J. \& Li, B. (2018). Carbon coated $\mathrm{MoS}_{2}$ nano sheets vertically grown on carbon cloth as efficient anodeforhigh-performance sodium ion hybrid capacitors. Electrochimica Acta, 283, 36-44. https://doi.org/10.1016/j.electacta.2018.06.082

Chen, P.A., Cheng, H.C. \& Wang, H.P. (2018). Activated carbon recycled frombitter-tea and palm shell wastes for capacitive desalination of saltwater. Journal of cleaner Production, 174, 927-932. https://doi.org/10.1016/j. jclepro.2017.11.034

Coplas, F., Tarón, A. \& González, R. (2017). Área superficial de carbones activados y modificados obtenidos del recurso agrícola Sacharum officinarum. Rev. Cienc. Agr., 34(2), 62-72. https://dx.doi.org/10.22267/rcia.173402.72.

Cordero-Lanzac, F., García-Mateos, F. J., Rosas, J. M., Rodríguez-Mirasol, J. \& Cordero, T. (2018). Flexible binderless capacitors based on $\mathrm{P}$ - and $\mathrm{N}$-containing fibrous activated carbons from denim cloth waste. Carbon, 139, 599-608. https://doi.org/10.1016/j.carbon.2018.06.060

Costa, P., Alves, J., Azevedo, D. \& Bastos, M. (2017). Preparation of biomass-based activated carbons and 
their evaluation for biogas up grading purposes. Industrial Crops \& Products, 109, 134-140. https://doi. org/10.1016/j.indcrop.2017.08.017.

Duan, X., Srinivasakannan, C., Wang, X., Wang, F. \& Liu, X. (2017). Synthesis of activated carbon fibers from cotton by microwave induced $\mathrm{H}_{3} \mathrm{PO}_{4}$ activation. Journal of the Taiwan Institute of Chemical Engineers, 70, 374-381. https://dx.doi.org/10.22267/rcia.173402.72.

Estévez Mujica, C. F., Moreno-Pirajan, J. C. \& Vargas, E. M. (2006). Obtención, caracterización y ensayo de telas de carbón activas. Revista de Ingeniería, 23, 68-75. https:// dx.doi.org/10.16924.

Feng, L., Li, G., Zhang, S. \& Zhang, Y. X. (2017). Decoration of carbon cloth by manganese oxides for flexible asymmetric. Ceramics International, 43, 8321-8328. http://dx.doi.org/10.1016/j.ceramint.2017.03.168

Fernández, J., Bonastre, J., Molina, J., del Río, A. I. \& Cases, F. (2017). Study on the specific capacitance of an activated carbon cloth modified with reduced graphene oxide and polyaniline by cyclic voltammetry. European Polymer Journal, 92, 194-203. http://dx.doi.org/10.1016/j. eurpolymj.2017.04.044

García-Ruíz, J. P. \& Díaz Lantada, A. (2018). 3D Printed Structures Filled with Carbon Fibers and Functionalized with Mesenchymal Stem Cell Conditioned Media as In Vitro Cell Niches for Promoting Chondrogenesis. Materials, 11(23), 1-14. https://doi.org/10.3390/ ma11010023

Ghiabi, C., Ghaffarinejad, A., Kazemi, H. \& Salahandish, R. (2018). In situ, one-step and co-electrodeposition of graphenes upported dendritic and spherical nanopalladium-silver bimetallic catalyst on carbon cloth for electro oxidation of methanol in alkaline media. Renewable Energy, 126, 1085-1092. https://doi. org/10.1016/j.renene.2018.04.040

Gineys, M., Benoit, R., Cohaut, N., Béguin, F. \& DelpeuxOuldriane, S. (2016). Grafting of activated carbon cloths for selective adsorption. Applied Surface Science, 370, 522-527. http://dx.doi.org/10.1016/j.apsusc.2015.11.257

Gineys, M., Benoit, R., Cohaut, N., Béguin, F. \& DelpeuxOuldriane, S. (2017). Behavior of activated carbon cloths used as electrode in electrochemical processes. Chemical Engineering Journal, 310, 1-12. http://dx.doi. org/10.1016/j.cej.2016.10.018

Giraldo, L. \& Moreno, J. C. (2004). Determinación de la entalpía de inmersión y capacidad de adsorción de un carbón activado en soluciones acuosas de plomo. Rev. Colomb. Quim., 33(2), 87-97. https://doi:10.15446/rev. colomb.quim

Gudarzi, D., Ratchananusorn, W., Turunen, I., Heinonen, M. \& Salmi, T. (2015). Factors affecting catalytic destruction of $\mathrm{H}_{2} \mathrm{O}_{2}$ by hydrogenation and decomposition over $\mathrm{Pd}$ catalyst supported on activated carbon cloth (ACC). CatalysisToday, 248, 69-79. http://dx.doi.org/10.1016/j. cattod.2013.12.050

Guedidi, H., Reinert, L., Soneda, Y., Bellakhal, N. \& Duclaux, L. (2014). Adsorption of ibuprofeno from aqueous solution on chemically surface-modified activated carbon cloths. Arabian Journal of Chemistry, 10, 83584-83594. http://dx.doi.org/10.1016/j.arabjc.2014.03.007

Hernández, D., Jiménez, F., Mondragón, F. \& López, D. (2007). Almacenamiento de Hidrógeno en carbones activados por oxidación con aire. Revista Energética, 37, 5-12. https://DOI:10.15446/energetica

Hernández-Rodríguez, M., Otero-Calvis, A., FalcónHernández, J. \& Yperman, Y. (2017). Physicochemical Characteristic of Activated Carbon of Coconut Shell Modified with $\mathrm{HNO}_{3}$. Rev. Cubana Quím., 29 (1), 26-38.

Hong-mei, H., Phillips, G.J., Mikhalovsky, S.V. \& Lloy, A.W. (2008). In vitro cytotoxicity assessment of carbon fabriccoated with calcium phosphate. New Carbon Materials, 23(2), 139-143. https://doi.org/10.1016/ S1872-5805(08)60017-7

Hu, M., Zhang, Z., Atkinson, J.D., Rood, M.J., Song, L. \& Zhang, Z. (2019). Porous materials for steady-state NO conversion: Comparisons of activated carbon fiber cloths, zeolites and metal-organic frameworks. Chemical Engineering Journal, 360, 89-96.https://doi. org/10.1016/j.cej.2018.11.102

Huang, C. C. \& Su, Y. J. (2010). Removal of copperions from waste water by adsorption/electrosorption on modified activated carbon cloths. Journal of Hazardous Material, 175, 477-483. https://doi.org/10.1016/j. jhazmat.2009.10.030

J. Filippín, A., S. Luna, N., T. Pozzi, M. \& D. Pérez, J., (2017). Obtención y caracterización de carbón activado a partir de residuos olivícolas y oleícolas por activación física. Avances en Ciencias e Ingeniería, 8(3), 59-71.

Jeon, H., Jeong, J.M., Hong, S.B., Yang, M., Park, J., Kim, D.H., Hwang, S.Y. \& Choi, B.G. (2018). Facile and fast microwave-assisted fabrication of activated and porous carbon cloth composites with graphene and $\mathrm{MnO}_{2}$ for flexible asymmetric supercapacitors. Electrochimica Acta, 280, 9-16. https://doi.org/10.1016/j.electacta.2018.05.108

Kilic M., Apaydin-Varol, E. \& Pütün, A. E. (2011). Adsorptive removal of phenol from aqueous solutions on activated carbon prepared from to bacco residues: Equilibrium kinetics and thermodynamics. J. Hazard. Mat., 189 (1-2), 397-403. https://doi.org/10.1016/j.jhazmat.2011.02.051

Kim C., Srimuk, P., Lee, J. \& Fleischmann, S. (2017). Influence of pore structure and cell voltage of activated carbon cloth as a versatile electrode material for capacitive deionization. Carbon, 122, 329-335. http:// dx.doi.org/10.1016/j.carbon.2017.06.077

Kordek, K., Yin, H., Rutkowski, P. \& Zhao, H. (2018). Cobalt-based composite film son electrochemically activated carbon cloth as high performance over all water splitting electrodes. International Journal of 
Hydrogen Energy, 44(1), 23-33.https://doi.org/10.1016/j. ijhydene.2018.02.095

Kostoglou, N., Koczwara, C., Prehal, C., Terziyska, V., Babic, B., Matovic, B., Constantinides, G., Tampaxis, C., Charalambopoulou, G., Steriotis, T., Hinder, S., Baker, M., Polychronopoulou, K., Doumanidis, C., Paris, O., Mitterer, C. \& Rebholz, C. (2017). Nanoporous activated carbon cloth as a versatile material for hydrogen adsorption, selective gas separation and electrochemical energy storage. Nano Energy, 40, 49-64. http://dx.doi. org/10.1016/j.nanoen.2017.07.056

Kumita, M., Yamawaki, N., Shinohara, K., Higashi, H., Kodama, A., Kobayashi, N., Seto, T. \& Otani, Y. (2018) Methanol adsorption behaviors of compression-molded activated carbon fiber with PTFE. International Journal of refrigeration, 2018, 127-135. https://doi.org/10.1016/j. ijrefrig.2018.07.036

Laxman, K., ZarMyint, M. T., Al Abri, M., Sathe, P.,Dobretsov, S. \& Duttaa, J. (2015). Desalination and disinfection of inland brackish ground water in a capacitive deionization cellusing nanoporous activated carbon cloth electrodes. Desalination, 362, 126-132. https://doi.org/10.1016/j. desal.2015.02.010

Leyva Ramos, R., Díaz Flores, P. E., Guerrero Coronado, R. M., Mendoza Barrón, J. \& Aragón Piña, A. (2004). Adsorción de Cd (II) en solución acuosa sobre diferentes tipos de fibras de carbón activado. Rev. Soc. Quím. Méx., 48, 196-202.

Li, N., An, J., Wang, X., Wang, H., Lu, L. \& Ren, J.R. (2017). Resin-enhanced rolling activated carbon electrode for efficient capacitive deionization. Desalination, 419, 2028. http://dx.doi.org/10.1016/j.desal.2017.05.035

Lin, Y. H., Hsu, W. S., Chung, W. Y., Ko, T. H. \& Lin, J. H. (2014). Evaluation of various silver-containing dressing on infected excision wound healing study. Journal of Materials Science: Materials in Medicine, 25, 13751386. https://doi.org/10.1007/s10856-014-5152-1

Ling, J., Zou, H., Yang, W., Chen, W., Lei, K. \& Chen, S. (2018). Facile fabrication of polyaniline/molybdenum trioxide/activated carbon cloth composite for supercapacitors. Journal of Energy Storage, 20, 92-100. https://doi.org/10.1016/j.est.2018.09.007

Liu, Y., Fan, Y.S. \& Liu, Z.M. (2019). Pyrolysisofironphthalocyanine on activated carbon as highly efficientnon-noble metal oxygen reduction catalyst in microbial fuel cells. Chemical Engineering Journal, 361, 416-427. https://doi.org/10.1016/j. cej.2018.12.105

López Peñalver, J., Linares-Fernández, J. L., de Araujo Farías, V., López-Ramón, M. V., Tassi, M., Oliver, F. J., MorenoCastilla, C. \& Ruiz de Almodóvar, J. M. (2009). Activated carbon cloth as support form esenchymalstem cell growth and differentiation toost eocytes. Carbon, 47, 3574-3577. https://doi.org/10.1016/j.carbon.2009.08.016
López, D., Hoyos, J.A. \& Mondragón, F. (2011). Adsorción catalítica de NO a baja temperatura sobre monolitos de carbón activado. Revista Facultad de Ingeniería Universidad de Antioquia, 57, 75-84.

Lozano-Castello, D., Alcaniz-Monge, J., De la Casa-Lillo, M. A., Cazorla-Amorós, D., \& Linares-Solano, A. (2002). Advances in the study of methane storage in porous carbonaceous materials. Fuel, 81(14), 1777-1803. https:// doi.org/10.1016/S0016-2361(02)00124-2

Luna, D., González, A., Gordon, M., \& Martín, N. (2007). Obtención de carbón activado a partir de cáscara de coco. Contactos, 67, 39-48.

Masson, S., Gineys, M., Delupeux-Ouldriane, S., Reinert, L., Guittonneau, S., Beguin, F. \& Duclaux, L. (2016). Single,binary, and mixture adsorption of nine organic contaminants onto a microporous and a microporous/ mesoporous activated carbon cloth. Microporous and Mesoporous Materials, 234, 24-34. http://dx.doi. org/10.1016/j.micromeso.2016.07.001

Matatov-Meytal, Y. \& Sheintuch, M., (2002). Review Catalytic fibers and cloths. Applied Catalysis A: General, 231, 1-16.

Matovic, L. L., Vukelic, N. S., Jovanovic, U. D., Kumric, K. R., Krstic, J. B., Babic, B. M. \& Dukic, A. B. (2016). Mechano chemically improved surface properties of activated carbon cloth for the removal of $\mathrm{As}(\mathrm{V})$ from aqueous solutions. Arabian Journal of Chemistry, (enimpresión ) http://dx.doi.org/10.1016/j.arabjc.2016.07.004

Mena Aguilar, K. M., Amano, Y. \& Machida, M. (2016). Ammonium persulfate oxidized activated carbonfiber as a high capacity adsorbent for aqueous $\mathrm{Pb}$ (II). Journal of Environmental Chemical Engineering, 4, 4644-4652. http://dx.doi.org/10.1016/j.jece.2016.10.028

Menéndez-Díaz, J. A. \& Martín-Gullón, I. (2006). Types of carbon adsorbents and their production. Interface Science and Technology, 7, 1-47. https://doi.org/10.1016/S15734285(06)80010-4

Min, B. H., Choi, J. H. \& Jung, K. Y. (2018). Improved capacitived eionization of sulfonated carbon/titania hybrid electrode. Electrochimica Acta, 270, 543-551. https://doi.org/10.1016/j.electacta.2018.03.079

Mohan, D., Singh, K.P. \& Singh, V.K., (2006). Trivalentchromium removal from waste water usinglow cost activated carbon derived from agricultural waste material and activated carbon fabric cloth. JournalofHazardousMaterials B, 135, 280-295. https:// doi:10.1016/j.jhazmat.2005.11.075

Myint, M.T.Z. \& Dutta, Y. (2012). Fabrication of zinc oxide nanorods modified activated carbon cloth electrode for desalination of brackish water using capacitive deionization approach. Desalination, 305, 24-30. https:// doi.org/10.1016/j.desal.2012.08.010

Myint, M.T.Z., Al-Harthi, S. H. \& Dutta, Y. (2014). Brackish water desalination by capacitived eionization using zinc 
oxide micro/nanostructures grafted on activated carbon cloth electrodes. Desalination, 344, 236-242. https://doi. org/10.1016/j.desal.2014.03.037

Navarro, P. \& Vargas, C. (2010). Efecto de las propiedades físicas del carbón activado en la adsorción de oro desde medio cianuro. Revista de Metalurgia, 46(3), 227-239. https://doi:10.3989/revmetalm.0929

Nieto-Delgado, C., Partida-Gutiérrez, D. \& Rangel-Méndez, J.R. (2019). Preparation of activated carbon cloths from renewable natural fabrics and their performance during the adsorption of model organic and inorganic pollutants in water. Journal of Cleaner Production, 213, 650-658. https://doi.org/10.1016/j.jclepro.2018.12.184

Ocampo-Pérez, R., Orellana-García, F., Sánchez-Polo, M., Rivera-Utrilla, J., Velo-Gala, I., López-Ramón, M.V. \& Álvarez-Merino, M.A. (2013). Nitromidazoles adsorptionon activated carbon cloth from aqueous solution. Journal of Colloid and Interface Science, 401, 116-124. http://dx.doi.org/10.1016/j.jcis.2013.03.038

Oh, H. J., Lee, J. H., Ahn, H. J., Jeong, Y., Kim, Y. J. \& Chi, C. S. (2006). Nanoporous activated carbon cloth for capacitived eionization of aqueous solution. Thin Solid Films, 515, 220-225. https://doi.org/10.1016/j. tsf.2005.12.146

Oladunni, J., Zain, J.H., Hai, A., Banat, F., Bharath, G. \& Alhseinat, E. (2018). A comprehensive review on recently developed carbon based nanocomposites for capacitived eionization: From theory to practice. Separation and Purification Technology, 207, 291-320. https://doi. org/10.1016/j.seppur.2018.06.046

Ospina-Guarín, V. M., Buitrago-Sierra, R. \& López-López, D. P. (2014). Preparation and characterization of activated carbon from castor de-oiled cake. Tecnológicas, 17(32), 75-84.

Ouyang, T., Cheng, K., Yang, F., Jiang, J., Yan, J., Zhu, K., Ye, K.,Wang, G., Zhou, L. \& Cao, D. (2018). A general insituetching and synchronousheteroatom doping strategy to boost the capacitive performance of commercial carbon fiber cloth. Chemical Engineering Journal, 335, 638-646. https://doi.org/10.1016/j.cej.2017.11.009

Peng, C. W. \& Lin, H. C. (2017). Adsorption for Dyeson Activation Carbons from Japanese Cedar Wood Prepared by Precarbonization and Two-stage Composite Activations with Wood Ash and Steam. International Journalof Chemical Engineering and Applications, 8(4), 277-285. https://doi:10.18178/ijcea.2017.8.4.670

Rangel-Méndez, J.R. \& Streat, M., (2002). Adsorption of cadmium by activated carbon cloth: influence of surface oxidation and solution $\mathrm{pH}$. Water Research, 36, 1244 1252.https://doi.org/10.1016/S0043-1354(01)00343-8

Robles Andrade, S., Silva Rodrigo, R., García Alamilla, R., Ramos Galván, C. E., Carrizales Martínez, G., Sandoval Robles, G. \& Castillo Mares, A. (2006). Carbón activado modificado como soporte para catalizadores prototipo de HDS. Revista Mexicana de Ingeniería Química, 5(3), 279-284.

Rodríguez, G., Giraldo, L. \& Moreno, J. C. (2009). Immersion enthalpies of activated carbon cloths as physicalchemistry characterization parameter. Rev. Colom. Quim., 38(3), 435-445.

Rodríguez, G., Giraldo, L. \& Moreno, J.C. (2007). Preparation and characterization of activated carbon cloths influence of precursor of cotton. Rev. Colom. Quim., 36(1), 43-53.

Ryoo, M.W., Kim, J.H. \& Seo, G. (2003). Role of titania incorporated on activated carbon cloth for capacitive deionization of $\mathrm{NaCl}$ solution. Journal of colloid and interface science, 264, 414-419. https://doi:10.1016/ S0021-9797(03)00375-8

Sevilla, M., Fuertes, A. B. \& Mokaya, R. (2011). Preparation and hydrogen storage capacity of highly porous activated carbon materials derived from polythiophene. International Journal of Hydrogen Energy, 36, 1565815663. https://doi:10.1016/j.ijhydene.2011.09.032

Sieben, J. M., Morallón, E. \& Cazorla-Amorós, D. (2013). Flexible ruthenium oxide-activated carbon cloth composite prepared by simple electrodepositation methods. Energy, 58, 519-526. http://dx.doi. org/10.1016/j.energy.2013.04.077

Song, X., Liu, H., Cheng, L. \& Qu, Y. (2010). Surface modification of coconut-based activated carbon by liquidphaseoxidation and its effects on lead ion adsorption. Desalination, 255(1-3),78-83. https://doi.org/10.1016/j. desal.2010.01.011

Thamiselvan, A., Govindan, K., Samson Nesaraj, A., Uma Maheswan, S., Oren, Y., Noel, M. \& James, E. J. (2018). Investigation on the effect of organic dye molecules on capacitive deionization of sodium sulfate salt solution using activated carbon cloth electrodes. Electrochimica Acta, 279, 24-33. https://doi.org/10.1016/j. electacta.2018.05.053

Tongpoothorn, W., Sriuttha, M., Homchan, P., Chanthai, S. \& Ruangviriyacha, C. (2011). Preparation of activated carbon derived from Jatropha curcas fruit Shell by simple thermochemical activation and characterization of their physicochemical properties. Chem. Eng. Res. Des., 89(3), 335-340. https://doi.org/10.1016/j.cherd.2010.06.012.

Tripathi, N. K., Singh, V. V., Sathe, M., Thakare V. B. \& Singh, B. (2018). Activated Carbon Fabric: An Adsorbent Material for Chemical Protective Clothing. Defence Science Journal, 68(1), 83-90. https://DOI:10.14429/ dsj.68.11734

Wang, H., Deng, J., Xu, C., Chen, Y., Xu, F., Wang, J. \& Wang, Y. (2017). Ultramicroporous carbon cloth for flexible energy storage with high a real capacitance. Energy Storage Materials, 7, 216-221. http://dx.doi. org/10.1016/j.ensm.2017.03.002

Wei, Y., Wang, R., Meng, L., Wang, Y., Li, G., Xin, S., Zhao, X. \& Zhang, K. (2017). Hydrogen generation from 
alkaline $\mathrm{NaBH}_{4}$ solution using a dandelion-like $\mathrm{Co}$ Mo-B catalyst supported on carbon cloth. International Journal of Hydrogen Energy, 42(15), 9945-9951. https:// doi.org/10.1016/j.ijhydene.2016.12.130

Yoda, T., Shibuya, K. \& Myoubudani, H. (2018). Preparation of activated carbon fibers from mixtures of cotton and polyester fibers. Measurement, 125, 572-576. https://doi. org/10.1016/j.measurement.2018.05.044

Zhang, Ch., He, D., Ma, J., Tang, W. \& Waite, T.D. (2018). Faradaic reactions in capacitived eionization (CDI) problems and posibilities: A review. Water Research, 128,
314-330. https://doi.org/10.1016/j.watres.2017.10.024 Zhao, F., Rahunen, N., Varcoe, J. R., Chandra, A., AvignoneRossa, C., Thumser, A. E. \& Slade, R. C. (2008). Activated carbon cloth as anode for sulfate removal in a microbial fuel cell. Environ. Sci. Technol., 42 (13), 49714976. https://DOI:10.1021/es8003766

Zou, N., Nie, Q., Zhang, X., Zhang, G., Wang, J. \& Zhang, P. (2019). Electrothermal regeneration by Joule heat effect on carbon cloth based $\mathrm{MnO}_{2}$ catalyst for long-term formaldehyde removal. Chemical Engineering Journal, 357, 1-10. https://doi.org/10.1016/j.cej.2018.09.117 